\title{
intuitio
}

Revista do PPG em Filosofia da PUCRS

http://dx.doi.org/10.15448/1983-4012.2019.2.33943

\section{DIZER VERDADEIRO SOBRE SI MESMO EM LES AVEUX DE LA CHAIR}

\section{TELL TRUE ABOUT YOURSELF IN LES AVEUX DE LA CHAIR}

\author{
Cleiton Nery de Santana ${ }^{1}$
}

Resumo: Les aveux de la chair (As confissões da carne) foi publicada na França em março de 2018. Esta obra póstuma de Michel Foucault aparece como o quarto volume da História da Sexualidade. Como um arqueólogo do saber, ele busca no cristianismo primitivo a origem e a evolução do cuidado de si. Nesta presente resenha, não abordaremos todos os temas tratados na obra, mas faremos um recorte sobre o tema da confissão presente na história do cristianismo primitivo. Desta maneira, Foucault encontra na matriz cristã as bases para a compreensão da hermenêutica do sujeito.

Palavras-chave: Michel Foucault. Hermenêutica do sujeito. Cristianismo.História da Sexualidade.

\begin{abstract}
Les aveux de la chair was published in France, in March 2018. This posthumous work by Michel Foucault appears as the fourth volume of The History of Sexuality. As an archeologist of knowledge, he seeks in primitive Christianity for the origin and evolution of care of the self. This review will not cover all the themes presented in the original study, but focus on confession, a theme that can be found in the history of early Christianity. By studying the Christian matrix, Foucault could define the bases for understanding the hermeneutics of the subject.
\end{abstract}

Keywords: Michel Foucault. Hermeneutics of the subject. Christianity. The History of Sexuality.

\footnotetext{
1 Pontifícia Universidade Católica de São Paulo (PUC-SP). ORCID: http://orcid.org/o0oo-00027702-9886. E-Mail:nery.sj@hotmail.com
} 
Les aveux de la chair é o quarto e último volume da História da Sexualidade escrito por Michel Foucault. Para uma melhor compreensão da origem e publicação desta obra, faz-se necessário conhecer o seu contexto. Em 1976, Foucault publica o primeiro volume, A vontade de saber, onde ele afirma que a sociedade burguesa não reprimiu o sexo, mas que a partir do século XVII a sexualidade deu lugar a uma série de discursos, se tornando um objeto para o saber. Foi no ano de 1984, pouco antes da sua morte, que Foucault publicou o segundo e o terceiro volumes, respectivamente $O$ uso dos prazeres e $O$ cuidado de si. $O$ segundo volume se concentra sobre os gregos do século IV a.C., que buscam dominar os elos do corpo e do amor. Quanto ao terceiro volume, trata sobre o início do período romano, que se preocupa com o cuidado de si.

Em suas pesquisas sobre a História da Sexualidade, Foucault também se interessa pelo cristianismo primitivo e por esta razão passa a ler os Padres da Igreja. Foi entre os anos de 1981-1982 que ele começou a redigir Les aveux de la chair. O manuscrito, já tendo sido corrigido por Foucault, foi publicado apenas em março de 2018 em uma edição organizada por Frédéric Gros. Este quarto volume da História da Sexualidade está organizado em três partes e quatro anexos: I - A formação de uma nova experiência; II - Ser virgem; III - Ser casado; IV - Anexos

Qual a novidade que Foucault traz nesta obra? Para ele, o cristianismo apresenta uma nova forma de subjetividade, na relação do sujeito consigo mesmo através da carne. No cristianismo primitivo, a vida do corpo e do espirito são reguladas por novas práticas, que obrigam o cristão a manifestar a sua verdade através da confissão e do exame de consciência. Estas novas práticas de tecnologia de si são desenvolvidas sobretudo no primeiro capítulo do livro. Foucault problematiza as técnicas de subjetivação vividas no cristianismo primitivo através do pensamento dos Padres gregos e latinos.

Nesta obra, também perceberemos como Michel Foucault busca compreender na história cristã a origem da obrigação ritualizada da verdade seguida do momento em que o sujeito verbaliza um dizer verdadeiro sobre ele mesmo. Em Les aveux de la chair, Foucault apresenta a origem do dizer 
verdadeiro sobre si mesmo presente nas práticas cristãs da penitência e do exame de consciência. Esta nossa resenha consistirá no primeiro capítulo da obra, seguindo a ordem apresentada por Foucault. Não trataremos aqui da primeira parte, que tem como tema a criação e procriação. Portanto, apresentaremos na seguinte ordem: I - Le baptême laborieux (O batismo); II - La seconde pénitence (A penitência); III - L'art des arts (O exame de consciência).

\section{I - Le baptême laborieux (O batismo)}

Nos primeiros dois séculos de existência do cristianismo, o batismo é o único rito através do qual as faltas são perdoadas, pois ele lava o pecado, marca a pertença do batizado à comunidade cristã, constitui um novo nascimento e ilumina a alma. Para Michel Foucault, cada uma das atribuições dadas ao batismo tem dois mecanismos: o primeiro de remissão dos pecados e o segundo de acesso à verdade. Uma vez que as faltas são apagadas pelo batismo, a alma recebe a luz da verdade.

Foucault também mostra que a evolução do batismo dá lugar a uma penitência, que aos poucos vai se desenvolvendo e se modificando nas primeiras comunidades cristãs. Antes de receber o batismo, o catecúmeno deveria conhecer a verdade de suas faltas, pois neste processo a metanoia e a penitência são inseparáveis.

Podemos perceber que a penitência mencionada por Foucault neste momento da história ainda não é uma prática penitencial desenvolvida e regrada, mas apenas uma tomada de consciência das faltas cometidas diante de Deus e de si próprio, que serve de motivação para o catecúmeno buscar por uma mudança de vida. As mudanças começam a acontecer com Tertuliano entre os séculos I e II. Com ele, o tempo da preparação ao batismo se torna mais importante, dando-se uma maior duração ao catecumenato.

Desta forma, o tempo de preparação para receber o batismo não se limita apenas aos ensinamentos dados pelo catequista, mas o catecúmeno é conduzido a descobrir a sua própria fraqueza e compreender que a sua confiança deve ser depositada em Deus. Esta preparação não é apenas um 
tempo durante o qual se rompe com a vida anterior, mas uma exortação a se desapegar, sem interrupção, de si mesmo.

\section{II - La seconde pénitence (A penitência)}

Para falar da penitência fora do batismo, Foucault cita uma passagem de O Pastor, escrito por Hermas, explicando que no cristianismo primitivo não existia outra penitência além do batismo. A questão colocada por Foucault é sobre o modo de institucionalização do ato de pecar após o batismo e da possibilidade de purificar-se. Diante da situação de pecado, se pedia com lágrimas a penitência para lavar as faltas cometidas após o batismo.

Desde Ambrósio, a salvação que não era obtida pelo batismo, pois o batizado continuava a pecar, devia ser buscada sob a forma de penitência. Por esta razão, o modelo ritual do batismo e a sua teologia começaram a sofrer alterações, pois os catecúmenos eram considerados penitentes. Assim, a penitência não é mais um ato, mas um estado. Quando a penitência termina, muitas vezes depois de anos, o cristão é admitido à reconciliação. Aquilo que interessa de modo particular a Foucault, é que no caso da penitência, os procedimentos destinados a manifestar a verdade da alma penitente são numerosos, que vão do testemunho daqueles que aceitaram enfrentar o martírio à manifestação do remorso do penitente.

Desta forma, na penitência dá-se um duplo movimento, primeiro o pedido confidencial ao padre ou ao bispo para entrar no estado de penitência e segundo, o que Foucault apresentará como a exomologese, que é a suplicação e a confissão pública das faltas. Não se trata apenas de fazer penitência, mas de manifestá-la exteriormente para que se possa dizer que a fez. A Igreja colocou o caráter fundamental de obrigação de verdade para aqueles que pecaram e que desejam se reconciliar, devendo manifestar em sua verdade seu estado de pecador, como forma indispensável para que o pecado seja perdoado.

Para justificá-lo, a Igreja recorreu a vários modelos. No modelo médico, é preciso expor suas feridas ao médico para que ele possa curá-las. No modelo judiciário, é preciso expor todas as circunstâncias e nada omitir, sob pena de ser 
culpado desta omissão. E no caso do martírio, particularmente importante no início da Igreja, aquele que se submete tem todos os seus pecados perdoados. Portanto, aquele que faz penitência é o cristão que não teve suficiente força para sofrer o martírio. A penitência deve ser uma forma de viver o martírio sem o derramamento de sangue. Foucault conclui dizendo que na história da prática penitencial, séculos mais tarde, o pecador deverá se apresentar ao padre e confessar verbalmente com detalhes as suas faltas: ego sum.

\section{III - L'art des arts (O exame de consciência)}

A direção espiritual e o exame de consciência remontam a uma antiga tradição filosófica, a que Foucault faz menção através de exemplos encontrados em Sêneca. No cristianismo, estas práticas só são introduzidas tardiamente. Será na vida monástica, vida filosófica segundo o Cristo por excelência, que o exame de consciência nascerá. Assim, a arte da direção espiritual é considerada por Gregório de Nazianzeno, como era para a filosofia, a arte das artes. A exagoreusis, presente nas primeiras comunidades monásticas, consiste no constante exame de si-mesmo. Para analisar estas práticas de exame e de direção, Foucault se refere sobretudo ao Padre João Cassiano.

A vida do monge, assim como para aquele que quer ter uma vida de perfeição, não pode ser considerada sem direção. Para ser dirigido, é preciso aprender a obedecer. A relação com a obediência deve atravessar a existência, pois o que conta na obediência é a sua forma. É preciso obedecer imediatamente, sem se revoltar, e mesmo se a ordem é absurda e esta obediência não tem outro fim que ela mesma. A paciência e a humildade são indissociáveis desta forma extrema de obediência. Assim, vemos a diferença entre a direção estóica, que buscava estabelecer condições de um exercício soberano da vontade sobre si-mesmo, e a direção cristã que tem por finalidade a renúncia à vontade.

Ao longo da sua existência monástica, o monge que busca a perfeição, deve evitar sobretudo dois perigos: de um lado o relaxamento com relação às obrigações da vida ascética e do outro o excesso de zelo, que também pode 
conduzir ao mesmo fim. Pois são as pequenas faltas que levam às graves. Para o monge não cair nestes dois extremos, Cassiano faz um apelo a discretio. Ele dá a esta noção uma importância fundamental e a implica de forma particular na luta contra os excessos do ascetismo. Além da graça divina, a discretio exige o exercício e a aprendizagem, sob o olhar do diretor a quem se confia. Esta é a distinção cristã da rememoração praticada por Sêneca.

Mas se o exame é interior, como saber de onde vem os pensamentos? Como o pensamento que se forma no exame é mais seguro do que aquele que é examinado? É este o paradoxo que justifica a confissão, que deve ter sua proximidade do exame de consciência. Neste exercício de verbalização, que é a confissão, há uma palavra que é dirigida a um outro. Uma palavra que se encontrará constantemente no vocabulário da penitência e da direção das almas: la virtus confessionis.

A confissão tem uma força operatória que lhe é própria: o sujeito diz, mostra e expulsa. Por esta razão, a discretio não pode ser reduzida a um simples exame de si, mas deve ser praticada sob a forma de uma confissão. Comparando o exame e a confissão no monaquismo com o exame filosófico pagão, Foucault estabelece um certo número de diferenças: no monaquismo, é uma obediência absoluta que é exigida, proibindo toda forma de autonomia, enquanto na prática filosófica pagã o exame é o encontro com a sabedoria filosófica. Esta prática dos monges trata daquilo que se apresenta à alma, enquanto que a prática filosófica do exame é sobre os elementos definidos (verdade/falsidade das representações, atos ou infrações).

Podemos concluir, a partir da leitura deste primeiro capítulo de Les aveux de la chair, que no cristianismo primitivo, a veridicção sobre si mesmo está ligada fundamentalmente à renúncia do si mesmo. Assim, o constante trabalho para dizer verdadeiro sobre si mesmo é um trabalho de mortificação. Podemos afirmar também que, o conceito de 'cuidado de si', desenvolvido por Foucault, tem a sua origem na filosofia grega antiga. Desta maneira, na busca de verificar as influências da filosofia grega sobre a espiritualidade cristã, ele apresenta a passagem de um ascetismo pagão para um ascetismo cristão. Por fim, a hermenêutica do sujeito, ou seja, a interpretação do 
homem sobre si mesmo, não está fundada no sacrifício ou na renúncia de si, como nos apresenta o cristianismo, mas na afirmação do sujeito.

\section{Referências}

CHEVALIER, P. O cristianismo como confissão em Michel Foucault. In: CANDIOTO, C.; SOUZA, P. (org.). Foucault e o Cristianismo. Belo Horizonte: Autêntica, 2012.FOUCAULT, M. História da Sexualidade 1. A vontade de saber. São Paulo: Paz \& Terra, 2015.

FOUCAULT, M. História da Sexualidade 2. O uso dos prazeres. São Paulo: Paz \& Terra, 2015.

FOUCAULT, M. História da Sexualidade 3. O cuidado de si. São Paulo: Paz \& Terra, 2015.

FOUCAULT, M. Histoire de la sexualité 4. Les aveux de la chair. Paris: Ed. Gallimard, 2018. https://doi.org/10.1086/701002

FOUCAULT, M. Malfazer, dizer verdadeiro. São Paulo: Martins Fontes, 2018.

\section{Endereço Correspondência:}

R. Monte Alegre, 984 - Perdizes, São Paulo - SP, 05014-901 